\title{
OS "MEIOS DE PRODUÇÃO DA DEFINIÇÃO": DESENVOLVIMENTO, REGIONALIZAÇÃO E PODER NA AÇÃO DISCURSIVA DO ESTADO NO BRASIL
}

Mário Henrique Castro Benevides

é professor adjunto da Universidade da Integração Internacional da Lusofonia Afro-Brasileira (Unilab).

Redenção, CE. Brasil. E-mail: <mario.castro@unilab.edu.br>.

http://dx.doi.org/10.1590/0102-221257/101

Os conceitos em sociologia política têm servido como instrumento interpretativo das relações mais agudas entre aparatos organizacionais e suas instâncias de autoimagem. A análise dos sistemas de publicidade estatal ou de "comunicação pública”, por exemplo, emerge em um mundo de redistribuição da transparência das ações dos entes públicos que vem migrando de mecanismos técnicos e culturalmente restritos como os diários oficiais para perfis ou páginas em redes de compartilhamento de informação, ao mesmo tempo em que disputa novas falas sobre progresso, modernização ou desenvolvimento como razão de ser da máquina pública. Acompanhar essas mudanças de comportamento burocrático em busca de camadas de legitimação passou a ser uma rota de investigação necessária para todas as facetas de uma sociologia do político. $\mathrm{O}$ discurso da mudança e das diretrizes que a guiam e a produzem trespassa a fala do e sobre o Estado desde que este passou a ser abordado como lugar de disputa ontológica das forças sociais (organizadas ou não) e de suas percepções de si. Não é diferente no caso de novas abordagens teóricas e históricas das instituições no 
Brasil. Este texto articula a flexibilização da noção de "meio de produção" de uma sociologia que também é uma economia política do simbólico (BOURDIEU, 1992), visando tratar os eixos entre o desenvolvimento como discurso e a máquina estatal como agente produtora de determinações sobre a transformação.

O Estado, também como conceito, exerce especial poder sobre a produção discursiva (e normativa) de territórios, grupos ou mesmo indivíduos. Ao intimar, delimitar ou conceber - por meio de políticas públicas ou execuções de legislação -, o poder público instaura espaços sociais e entra no jogo de forças da definição do que são lugares, sociabilidades e pessoas. Discutiremos essa propriedade estatal em três partes. $\mathrm{Na}$ primeira, analisando a ideia de desenvolvimento como recurso político fundante da modernidade e para a modernidade do Estado na história do século XX. Em segundo lugar examinaremos algumas dimensões teóricas do tema para as ciências 222 sociais, como conceito e raiz de discursos. Em seguida, uma rápida síntese histórica sobre o desenvolvimento no Brasil e, em particular, no Nordeste brasileiro se faz necessária para entendermos a lógica do poder de fala estatal de que tratamos. Nessa última parte, discutindo a retomada da noção de desenvolvimento nos dois governos Lula (2003-2006 e 2007-2010), período que mescla novos e velhos recortes da visão do Estado no país, o artigo abordará também a relação entre desenvolvimento e a necessidade de seu exame enquanto categoria de saber-poder nas ciências sociais ao trazer o tema da região e sua mudança como eixo do debate. De modo dialogado e também alicerçado na história como processo, o texto almeja apresentar os modos pelos quais o Estado adquiriu meios de definir seu próprio papel e os cenários concretos que abordava.

\section{Estado, modernidade e desenvolvimento}

Compreender os eixos que norteiam uma percepção sobre a mudança histórica no que ela tem de processual 
implica a aproximação com o Estado porque interpõe um diálogo com suas apropriações históricas que caracterizam seus alcances. Mas é também fundamental examinar o histórico de significados que o desenvolvimento relaciona. Compreender alguns dos elementos que constituem sua produção talvez nos aproxime mais da referência da expressão, em particular, dentro do pensamento social e de suas fundações e ligações à ação estatal e ao seu ciclo de formação de poder-saber.

Neste campo, observar os modos de apresentação do moderno é pauta primária. A ideia de modernidade, expressiva problemática da sociologia contemporânea, vem à tona na temática estatal como sinônimo frágil das definições de desenvolvimento e das definições de sua comunicação. Dessa forma, a compreensão do conceito de modernidade em seu passado teórico como ferramenta explicativa é ponto convergente que merece atenção para a compreensão mais completa do objeto que aqui pensamos. A modernidade é tratada nos clássicos como um tempo de promessas de melhoria nas condições de existência humana provocadas por um aprimoramento da gestão social dos problemas coletivos. Mais ainda: é tratada, no passado mais distante, como lugar temporal dos aprimoramentos técnicos em seus sentidos materiais e no sentido de uma reinvenção dos saberes administrativos - é Max Weber quem ressaltará esse segundo ponto, admitindo a modernidade como parâmetro para a compreensão das revoluções econômicas que fundam a sociedade ocidental de seu tempo e argumentando que a calculabilidade e o controle matemático dos empreendimentos é parte central de seu corpo (WEBER, 2004). Por fim, a modernidade, como será necessário analisá-la, rescinde os preceitos de uma vida tradicional governada por qualquer dinâmica que não seja própria de uma racionalização das práticas sociais, politicas, econômicas. É o tempo da elevação de ideais clássicos de domínio da ratio e de conquista de suas 
premiações presumidamente inerentes. É, desse modo, território, ainda que parcial, do nascimento do Estado contemporâneo, em seus matizes de controle, registro e apuração dos acontecimentos sociais.

Mais tarde, na produção de sua consolidação, a modernidade se verá atrelada a diversos modernismos, sejam movimentos culturais locais ou nacionais, que como atributo principal ensejam a vontade de situar sociedades ou grupos no jogo maior das reinvenções do mundo de então. $\mathrm{O}$ modernismo brasileiro, como exemplo ótimo de tais tendências, pautou-se em uma tentativa de romper com a tradição erudita da arte em prol da compreensão identitária otimizada de aspectos ignorados de nossa cultura. Era, nesse sentido, também uma racionalização da arte na medida da instauração da urgência política de se afirmar como autônomo e, como tal, parte do todo internacional igualmente convicto de suas autonomias - aparente contradição lógica, 224 mas verdade sustentada pelo poder da doutrina liberal tão forte, para a qual a igualdade era fruto de igualdade de potenciais e disposição espiritual.

Nas ciências sociais e nos campos intelectuais correlatos, a modernidade tornou-se objeto de dissecação e crítica ainda no fim do século XIX, com o próprio Weber e suas indicações ao "desencantamento" do mundo perante as novidades. A tônica de um tempo de acelerações e renovações incertas já estava presente nas análises dessa linha nietzschiana de interpretação dos processos. A modernidade era tematizada sem pudores. Ainda nos começos do século, o questionamento de suas possibilidades efetivas e de suas consequências reais motivou a produção de antigos e novos clássicos literários como Admirável mundo novo, 2001: uma odisseia no espaço, 1984 e Laranja mecânica, entre outras obras questionadoras das implicações desse "novo tempo".

Antes mesmo, a oposição a seus contornos já estava presente em trabalhos como os de Edgar Alan Poe ou Eça 
de Queiróz. Nietzsche já explorava os aspectos dissonantes e perturbadores do moderno - exercício que a Escola de Frankfurt conduziria sob outra vertente. Mas como essa modernidade se configura no quadro político observado? Como esse conceito chegou aqui, em meio ao debate sobre dinâmicas da publicação das intenções da máquina de governo?

A premissa da mudança social como progresso pode estar presente nas primeiras filosofias do século XIX, mas não nasceu ali. Ainda que seja uma profunda ingenuidade determinar a origem absoluta dessa orientação interpretativa sobre o mundo, é possível pensar os indícios de sua sociogênese ou, em termos mais diretos, de sua consolidação enquanto categoria do pensamento social ocidental. Assim surge a noção de que o "desenvolvimento" na forma de progresso é, incluindo sua dimensão linguística, um fruto das vontades positivistas. Como tal, deita raízes no Iluminismo do século XVIII e na concepção modular de que o homem pode, como ser político e centro da vida humana, desvelar os problemas de sua realidade e aprimorá-la enquanto existência terrena. Sob diversos aspectos - entre eles o da interpretação de uma nova economia das ações e projetos da humanidade -, o Iluminismo delineou as bases de uma "utopia laica". Revivendo os anseios de Tomas More sem se desfazer por completo de uma compreensão do mundo situada por Maquiavel, os revolucionários franceses e a base ideológica a eles atrelada sonhavam e trabalhavam com a realização de uma sociedade que pudesse ter a justiça e as demais virtudes-slogan da Revolução como núcleo. Não se trata aqui de negligenciar os movimentos e conflitos internos de 1789 e além - ou ainda de tomar uma leitura ingênua dos próprios iluministas como "seres de vontade e virtude". Cabe, ao contrário, reiterar e relembrar as bases imaginárias dos discursos por eles produzidos para melhor compreender como a ideia de "evolução social" será vendida nas décadas 
seguintes, em meio ao conturbado e acelerado curso político das transformações na Europa (DARNTON, 1990).

Se situarmos ainda que a própria Revolução será revista e alterada pelas ambições bonapartistas, seremos capazes de reconhecer que o produto imaginário da geração anterior ao Império Francês surgiu por sobre as marcas de solidez e poder que Napoleão conjurava sobre si e sobre a sociedade que pretendia modificar. O "progresso" não foi abandonado na lógica do Imperador. Ao contrário, foi sob suas vistas e interesses que a França testemunhou uma defesa resoluta da racionalização institucional e social. Mesmo sob a guarda carrancuda de um sistema político nada democrático oposto ao esperado pelas elites revolucionárias -, a França de Napoleão mantinha projetos de mudança voltados para destruir a ainda viva raiz tradicionalista francesa, abrindo assim caminho para a legitimação do próprio Império e seu passado violento. Necessário finalizar este ponto acrescen226 tando que o resto da Europa virá se alimentar de fragmentos diversificados e relativamente saborosos dos discursos de aprimoramento nacional. Aqui estará, resoluta, uma nova raiz: a do nacionalismo republicano em desenvolvimento. É nele, por meio de suas próprias pretensões enquanto vontade de grupos e novas elites, que a mudança social permanecerá um ideal alardeado universalmente e uma ação limitada a "harmonização" social - desejo de tantos dirigentes e de tantas oligarquias.

O começo do século XX trouxe suas próprias redefinições da modernidade. As revoluções e acelerações do processo industrial virão a reboque de uma intensa valorização da velocidade como máxima do aprimoramento social e econômico. A defesa da tecnologia e da racionalização das várias esferas da sociedade também é reforçada - assim como é retroalimentada pela defesa de uma pacificação profunda dos espaços ainda conturbados da vida coletiva e urbana. Mas a maior alteração será, sem dúvida, a consolidação do 
modelo republicano/parlamentar de governo, que instituirá, tanto na França, na Alemanha, na Inglaterra (com sua monarquia parlamentar) como nos Estados Unidos, um paradigma de administração pública cuja racionalização se dará por "saltos" constantes. A necessidade de órgãos e ministérios integrados atrairá a responsabilidade social da mudança conjuntural para dentro da máquina pública, instituindo a lógica do planejamento como elemento central do processo de organização das estruturas gestoras.

Podemos ver que a validade, a importância e a problematização do desenvolvimento têm raízes bem díspares, multiplicadas pela vastidão de suas causas. Como toda ideia ampla, sua "origem" se perde no sistema das polissemias e da arqueologia de suas possíveis acepções. Mas não é sem sentido retornar na esteira histórica do capitalismo industrial para examinar a sua ordenação nos termos da maioria de suas definições modernas. O desenvolvimento "aparece", portanto, já no século XVIII, como sinônimo de crescimento econômico e acúmulo de ativos, já na base inicial da discussão sobre riqueza e amadurecimento dos meios de produção como mecanismos de garantia dos interesses de determinados grupos - por que não dizer, de uma burguesia urbana, fixa, aliada ao já estruturado sistema financeiro-bancário da Europa nos estertores das revoluções do período (HOBSBAWM, 2005; LIMA, 2011).

Se for verdade que a Economia Política Clássica já sondava o problema do enriquecimento como caminho de inquietação, foi o positivismo que aderiu à problemática o sentido de planejamento social, incorporando o desenvolvimento como fragmento das intenções de intervenção. Estado e sociedade eram encaixados como peças - ou dois jogos de quebra-cabeça, para aprimorar a metáfora - de um sistema imaginário de identificação e resolução mecânica das desarmonias da existência coletiva avaliadas pela ciência positiva. Entre a ascensão napoleônica e a retomada da 
monarquia, amparada por setores conservadores da burguesia industrial da primeira metade do século XIX, temos uma revisão do desenvolvimento como estudo-e-ação sobre a pobreza, a insegurança, a insalubridade urbana e a defasagem competitiva que a França do período encarava ao jogar o jogo da revolução produtiva. Aos poucos, submetida à lógica de reinvenção inglesa, a classe dirigente no universo dos positivistas interventores era lentamente obliterada pelo crescimento de grupos de investidores e de estratégias econômicas anglo-saxãs (HOBSBAWM, 2005). Não irá demorar para que a amplitude proporcionada pelos mercados coloniais no novo mundo abaixo do Equador venha a tornar o império britânico o novo modelo de crescimento, deixando para a França o eco ainda duradouro de uma potência cultural e influente no campo simbólico das elites europeias e americanas, mas cada vez menos determinante na definição do papel do Estado no que diz respeito ao modelamento 228 das economias de intervenção pública. O liberalismo, transitando dos ingleses para os norte-americanos, vencerá a longa algazarra, pondo em xeque, nas esferas práticas e imediatas, o próprio entendimento do planejamento e da intromissão estatal no mundo do vivido (HOBSBAWM, 2005).

A sequência simplificada da mudança, tanto no formato do Estado como na correlata discussão de seus "usos", está na crise final do mundo colonial: a independência em larga escala e o surgimento de repúblicas burguesas completar-se-á na falência da escravidão na segunda metade do Oitocentos. O entendimento do livre mercado e a semente dos debates sociais por liberdade plena criam dois nichos políticos no sistema de relação Estado-Capital e na reorganização dos Estados-Nação como forças de transformação social: é como se a identidade do Estado moderno, cada vez mais burocratizado e racionalizado, aderisse a uma dependência para com os ideários de responsabilidade que o republicanismo reforçava nas décadas de 1880 e 1890. O século 
XX começará sob o signo da produtividade e das tentativas de ordenamento das promessas sociais.

Trata-se de um movimento que segue com o aprimoramento produtivo e as transformações no mundo do trabalho nas primeiras décadas - urbanização acelerada, atração de mão de obra das periferias econômicas para os centros de crescimento (ELIAS, 1998). A Primeira Guerra iniciará, em paralelo aos interesses de expansão da economia norte-americana e manutenção do esfacelado poderio britânico, um novo conjunto de apelos técnicos: o espasmo ou salto tecnológico que ganha sentido industrial no período virá traçar o desenho de um modelo diferenciado de crescimento, baseado na inventividade acelerada. Esta linha-mestra de concepção ontológica do que é acúmulo de riqueza, capital e mudança desdobrar-se-á no signo do desenvolvimento tal como o ouvimos em relatos e signos diversos.

A revolução soviética, por seu turno, surgirá e será expandida como contraponto parcial a essa lógica de acumulação de mercado. Se por um lado, na concepção da Revolução Russa, esse Estado fora redefinido seguindo a lógica de um aparelho de transformação política por via de um entendimento de coletivização de suas composições, por outro, na interpretação de Stálin, permanecerá uma aguda demanda por ampliação material dos esforços de acumulação técnica para a superação do mundo agrário do Leste, ironicamente ligando seu projeto aos modelos que buscava superar. Assim:

O desenvolvimentismo não foi apenas um projeto de Estados nacionais e impérios "burgueses", mas o foi também dos autodenominados socialistas. O problema cresceu quando os impérios, que justificavam seu domínio proclamando-se como agentes de modernidade e modernização, como instrumentos de desenvolvimento e progresso, realizaram muito bem a tarefa que se haviam 
proposto, propiciando a suas populações subordinadas as linguagens de aspiração e resistência. Na verdade, criaram súditos que não mais precisavam do império da maneira que os colonizadores pretendiam. (SUNY, 2008, p. 84)

Em Lênin, o desenvolvimento capitalista é um processo de acúmulo excludente que só poderia ser superado segundo uma nova forma de transformação da lógica de planejamento e ação. O desenvolvimento, tal como no modelo do Ocidente, recebe a dura crítica de um processo de mutilação da força de trabalho. Mas em Stálin, a recuperação da captura tecnológica e da acumulação da força industrial - sobretudo bélica - é condição necessária à consolidação de um "desenvolvimento alternativo" que acabará por deixar marcas aproximadas da proposta norte-americana (HOBSBAWM, 1986).

No Ocidente, o discurso de Harry S. Truman ${ }^{1}$, em 1949 230 (FAÉ, 2009), aloca uma carga de sentido inesgotável ao termo, através de um discurso que se tornou famoso (FAÉ, 2009). Entre outras coisas, ele conjura novos significados para o desenvolvimento, que antes tinham muito mais uma relação semântica com as ciências cognitivas (MELLO, 2009). A sequência de aparatos e valorações que o desenvolvimento no sentido econômico-social receberá nas décadas seguintes tem sua própria história dentro das preocupações estatais das potências americana e europeias: elas lidarão com a aflição estrutural da retomada do crescimento e do seu preço para a máquina pública. $\mathrm{O}$ tom da intervenção estatal fora transmutado. A relevância do abstrato aspecto financeiro e monetário obtinha uma vitória esmagadora contra as antigas políticas de incentivos simplificados - dito de outro modo, o controle fiscal e as ações de envolvimento público intermitente serão atreladas de maneira definitiva

1 Presidente dos EUA entre 1945 e 1953. 
às práticas de subsídio ao capital privado. Truman associa o crescimento fixo à noção de enriquecimento societário e humano e, com isso, deixa um marco discursivo em uma prática já ativa.

É importante entender que o Estado, refratário em sua natureza a qualquer continuísmo sistemático de intervenção, adentra no caminho de produção de desenvolvimentos modificados pelo mercado e pela base industrial cada vez mais complexa que o pós-guerra estabeleceu e alimentou. A nova era de tecnologias mutáveis do século XX foi não somente criada pela nova face econômica do capitalismo massivo: ela o afetou, integrando ao sistema de produção de mercadorias e desenho de mercados o ônus da inovação e da necessidade de subsidiá-la. Neste ponto, os fundos públicos são convocados como margem estratégica de incentivo, movimentados juntamente à criação de instituições internacionais capazes de legitimar e difundir a dinâmica que a economia americana refundava.

Cabe aqui uma reflexão cruzada: os desenvolvimentos anteriores, ainda no começo da modernidade positivista, já presumiam o eixo de participação do Estado como gerador de condições materiais e de legitimação ao inferirem seu papel de cérebro do organismo social? Ou é possível dizer que a criação prática de mecanismos institucionais foi a real responsável pela efetivação desse projeto moderno? Partindo de uma filiação inegável ao segundo postulado, afirmo que o desenvolvimento não emerge como propósito moderno real até a consolidação de seus projetos no interior da economia globalizada. É sua encarnação como política de continuidade que registra a vitória do paradigma no âmbito das elites gestoras. E com essa superação (carregada de todas as consequências que a compõem) estrutura a falência de um modelo de Estado interventivo socialmente preocupado, substituído pela imagem e práxis de um Estado interventivo economicamente envolvido. 
O acordo de Bretton Woods, visando vencer, ainda no começo do século, os efeitos da Grande Depressão, significou a validação do Estado como ente interventor organizado. A criação do Fundo Monetário Internacional, do Banco Mundial e de toda sua rede de mecanismos de controle econômico impuseram uma mitologia do controle: a industrialização precisava de planificação e os aparatos reguladores na forma de instituições tuteladas pelo Estado americano e seus aliados eram apresentadas como guias desse modelo.

A modernização no levantamento de dados e a implementação de uma constante vigilância no campo monetário e de investimentos complexificaram o sentido da intervenção e da ideia de crescimento. A racionalização adicional de órgãos de mercado (como a criação da Organização Mundial do Comércio, em 1993) apresenta o custo das demandas políticas ligadas a essa ideia. Os novos ciclos de 232 aceleração e a preocupação intermitente com o crescimento econômico transferiram a matemática hipercalculada para a noção de desenvolvimento renovada no pós-guerra - um transplante simbólico que converteu o segundo em um modelo quantitativo e marcado por índices dos mais variados (de inflação ao de Desenvolvimento Humano). É em tal contexto, portanto, que o levantamento sobre fatores como mortalidade infantil, índice de envelhecimento, abrangência de saneamento básico, alfabetização e número de homicídios são colocados no mesmo patamar: descritores do tipo e do estágio de desenvolvimento dos países vinculados à comunidade internacional.

\section{Desenvolvimento e Ciências Sociais}

A principal questão semântico-simbólica que gira em torno do desenvolvimento como promessa e prática incide nos modos pelos quais pensamos a mudança social no sentido de um rompimento da ordem ou da fragilidade das 
sociedades do passado - como uma recusa à memória ou sua revisão.

Se há uma relação profunda entre as proposições políticas do Estado no pós-guerra e os debates epistemológicos dentro das ciências sociais no século XX, o desenvolvimento na forma de mudança social está presente nela. Pensemos nisto por um instante: desde a fundação das filosofias da história e da concepção clássica de investigação sobre o mundo social temos discussões sobre as formas e os caminhos pelos quais as sociedades humanas têm mudado - sobretudo no sentido dos planejamentos macroeconômicos internos ao estudo sobre o capitalismo. A escola alemã deixa claro seu interesse (seja em Hegel, Marx ou Weber) na compreensão dos processos constituintes da história ocidental das mentalidades e suas consequências e causas. É nesse sentido que os temas dentro do invólucro da mudança social, de sua faceta de acumulação e alteração das estruturas produtivas, conectam-se para formar uma teia de sentidos econômico-políticos: uma interpretação de larga escala dos processos de comportamento e de vivência do homem recente.

Hegel e Marx têm suas responsabilidades iniciais nesse caminho. Entendendo a dinâmica do processo histórico como movimento (ideal ou material) das ações coletivas humanas, eles fundam as falas sobre história como sequência de encadeamentos de eventos, tomando dos gregos a ideia de mudança e a aplicando-a em seu sentido social e estrutural. Marx não transforma simplesmente a concepção de Heráclito ("tudo flui") ou a perspectiva reformada de Aristóteles (de um mundo impulsionado por um motor imóvel): ele as redimensiona, baseado no hegelianismo invertido, atribuindo ao tempo e aos movimentos do poder social um teor de causalidade e consequência indissociáveis.

Ainda que o positivismo tenha participado desse mesmo composto de ideários da mudança da realidade social (como veremos a seguir), é importante ressaltar que os debates 
sobre a economia e os processos de enriquecimento já estavam sendo profundamente debatidos pelos antecessores do materialismo histórico em um embate teórico que convocará David Ricardo, Adam Smith, Thomas Malthus e JeanBaptiste Say, conduzindo o pensamento filosófico alemão a desdobrar os meandros das crises sociais com antecedência relativa e maior profundidade (HUNT; SHERMAN, 2008).

Por outro lado, a leitura da mudança no sentido de evolução cumulativa da organização, racionalidade e adaptabilidade do homem enfrentou hibridismos. Temos, no século $\mathrm{XX}$, como que de contrabando das reflexões de Nietzsche e da antropologia mais crítica e interpretativa que nasce também de Max Weber, uma visão relativista e não matemática da transformação como sistema não linear, mas, ainda assim, a configuração de um esquema de acúmulos e adesões, pautado no entendimento de que somos melhores em relação a dado passado de precariedades - um dilema que 234 volta constantemente às discussões científicas. O rival desse argumento atesta uma linearidade oposta (mas ainda uma linearidade): a de que decaímos nos controles de nossa própria modernização, "involuindo" a estágios mais caóticos e tensos da existência como coletivo global.

Somando a essa equação as digressões teóricas que falam da diferença como elemento de mudança discutível, temos um novo problema, também inspirado na filosofia nietzschiana (e que afetou de diferentes modos as ciências humanas): a mudança social passa a ter um caráter qualitativo inviolável, protegido em si mesmo pela luta interminável pelas leituras livres e não rotuladoras da mudança como transição nem para o melhor, nem para o pior. A reflexão sobre a instabilidade das valorações do mundo e o caráter crítico-radical dessas filosofias derivadas (que fundarão o desconstrutivismo, a arqueologia de Michel Foucault (1999) e a sociologia de Jean Baudrillard (2007), para citar alguns exemplos) marcarão a mudança (e o 
desenvolvimento) como estruturas frágeis e modelos limitados de compreensão.

Em resumo, na disputa entre avaliações cumulativas e interpretações diferenciais e qualitativas, a teoria social atrelou-se à segunda (para a qual a mudança é uma questão relativa, de qualidade, não de quantidade) em detrimento de todos os vínculos e apoios que o senso comum político e gestor vem conduzindo a partir da epistemologia do primeiro tipo - já que, para o discurso político, o número, o passado, a acumulação de realizações, parece parte do capital que sustenta os grupos de poder. As consequências e a avaliação dessa separação precisam entrar no campo do debate sobre ideias e ideários que facilmente transitam entre os campos.

As iniciativas interpretativas brasileiras, em especial levadas a cabo desde o século XIX no tom da luta pela definição nacional juntamente com a formação de uma teoria social também local - incorporam o Estado como veículo de mudança já muito cedo - característica profundamente relacionada com o autoritarismo latente nos primeiros momentos de reflexão política no Brasil.

A base da relação entre Estado e desenvolvimento cruza os intérpretes clássicos sob duas matrizes fundamentais (ainda que estas se subdividam): de um lado o entendimento de um envolvimento do Estado como interventor estruturante, do outro, como o mediador entre forças produtivas e interesses de uma elite sempre com pretensões a inserção no cenário internacional. Algumas vezes essas visões se confundem. Outras vezes a gradação entre uma e outra assume um detalhismo considerável. Tentemos, aqui, ao menos, observar algumas delas.

É com os clássicos autoritários, como Alberto Torres, Oliveira Vianna ou Nestor Duarte, que o Estado assume um papel de intervenção multissetorial, atuando na sociedade civil com todas as responsabilidades de gerir suas descontinuidades e romper com suas fragilidades. Oliveira Vianna 
institui uma ideia de Estado nacional que não funcionaria sem o desenho de uma máquina controladora, ilimitada e vertical, parte do plano de mudança e estabilidade que a virada do século almejava - por meio das vontades da classe agrária abalada. No entendimento de Vianna (1999), apenas um mecanismo estatal determinado e centralizador poderia dar bases a uma realidade liberal futura (na forma de uma sociedade civil menos regulada). A historiografia epistemológica e cultural de Sérgio Buarque emprestará ao Estado um passado de estruturas parciais, montadas sob a memória de uma identidade ibérica e dúbia (no sentido das altercações entre planos de transformação do território colonial e uma cultura da aventura, da negação do trabalho). Ainda que observando a colônia, Buarque dá pistas para a compreensão de um passado de inventivas e desafios de tratamento da mudança. $\mathrm{O}$ historiador compreende o andamento da formação social dos aparelhos estatais na 236 direção de uma base intermitentemente afetada pelo patrimonialismo - e mais do que isso, incorpora uma teoria parcial do poder que atesta os graves impactos de uma histórica filosofia do Direito Privado sobre a elaboração de uma noção de Público tensamente deficitária.

Será o marxismo questionador de Caio Prado Júnior o primeiro a rever a lógica de dependência e metamorfose do Estado mercantilista, produzido como entidade sobrevivente nas transições sistemáticas que a economia (primeiro colonial, depois imperial e republicana) ensejava e levava a cabo. Nesse sentido, o Estado pradiano é um lócus de poder e ação de classes exploradoras em constante negociação - menos marcadas pelas rupturas drásticas que a Europa vivenciara e mais devotadas à manutenção de um "esqueleto político" que pudesse abrigá-las.

$\mathrm{O}$ teor interpretativo de Gilberto Freyre inseriu na temática da intervenção o caráter regionalista em uma revisão aguda e crítica de um Euclydes da Cunha. No acesso da 
pesquisa sobre nosso passado cultural e envolvido em sua própria parte do campo político, Freyre articula uma leitura do Estado (e de uma sociedade) cego à marca das regiões e suas singularidades ontológicas. A história, para o sociólogo pernambucano, é a prova das manifestações múltiplas de uma cultura imbricada e híbrida, que reagiu e reage às pressões globalizantes com teimosia e substância. Para ele, o Estado parece compor uma força capaz de adestrar os conflitos sociais e harmonizar o seu conteúdo, atribuindo à memória e ação presente uma forma pacificadora e "democrática" (tomando em conta que Gilberto Freyre se marcava por um otimismo histórico conhecido, pautado em uma leitura democrática contraditoriamente limitada na prática).

A primeira metade do século XX conjura, portanto, uma mixórdia de interpretações abalizadoras do Estado como ente de resolução ou como ferramenta definitiva da estruturação social. Nessa prateleira de avaliações clássicas, nosso passado e nossa formação processual estão implicados na longa e tenaz ausência desse corpo causador, dessa força de propensão que aparentemente não existia nem em nossa forma colonial, nem nas tentativas reformadoras de um Estado imperial independente, nem na nova velha ordem que a República Velha tentara instaurar. Tal ausência será preenchida ou pela fraqueza de instituições acossadas pelo privado ou pela instável combinação de conflitos de classe de poder que, em suma, são apenas formas diversas da mesma elite agrária que lentamente se moderniza.

É nesse ínterim que a revisão do papel da máquina pública ganha nuances de uma sociologia da civilização nacional. Ora retratada como letárgica, ora observada em sua dependência para com o planejamento de forças burocráticas, ora vista como massa controlada por classes à caça de uma economia de mercado. Marxismo, historiografia clássica e uma antropologia cultural à brasileira competiam no começo do século como modelos variantes de explicação 
das possibilidades e necessidades políticas de um Brasil ainda titubeante na determinação de seu projeto nacional.

A segunda metade do século trará a ampliação do debate marxiano atrelada à elevação de uma ciência política renovada. De um lado, Raimundo Faoro colocará o debate do poder como foco da observação de nossas instituições. Do outro, a escola de Florestan Fernandes terá a responsabilidade de refletir o materialismo histórico nos termos de uma nação agrária em processo de industrialização e urbanização.

Para Faoro (2008), o passado de ingerências das classes dominantes de grandes latifundiários abrirá largo precedente para um sistema de poder de elites ainda pouco racionais em um pano de fundo sem grandes oposições de movimentos organizados. Mais tarde, o coronelismo regional ou o mandatário padrão do sudeste cafeicultor se converterá na elite modernizadora carregada de estruturas tra238 dicionais de mando, em uma anulação contínua dos acessos da sociedade civil semianalfabeta e desprovida dos meios de organização e educação das primeiras.

Para Florestan Fernandes (ANO), a tardia revolução burguesa brasileira se dará à custa do Estado continuamente disputado por elites mercantis e forças retrógradas. Seguindo a esteira do materialismo crítico, o autor reconstrói a história econômica de Caio Prado na observação de uma máquina pública que se funda junto ao estabelecimento de uma burguesia nacional comprometida com a acumulação capitalista. A seguir, é com Fernandes que a base teórico-crítica das relações entre Estado e sociedade civil será pautada como uma análise incisiva dos dramas históricos de constituição de uma revolução burguesa com traços patrimoniais. A compreensão do Estado como agente da mudança será observada, pelas ciências sociais oriundas desse debate, com desconfiança. A história de estruturações da máquina pública e suas relações com trajetórias que 
remontam ao espaço colonial colocarão a interpretação do desenvolvimento sob um crivo de interesses limitados a elites renovadas.

Essas linhas interpretativas configuram algumas das dicotomias que mais tarde recortarão os diálogos e oposições. De um lado, uma compreensão do Estado como desenvolvedor de elementos fundamentais para o abandono de condições rurais no país - ideias-mãe da lógica desenvolvimentista. Do outro, um conjunto de críticas ao patrimonialismo que irá, direta ou indiretamente, fornecer subsídios para críticas ao poder público como poder de favorecimentos e tradicionalismos - uma realidade estatal que carecia, como enfatizarão os discursos, de uma modernização administrativa, cujos princípios serão abraçados pelas propostas neoliberais.

\section{Desenvolvimento no Brasil, imaginários desenvolvimentistas e região como eixo de ação}

A longa dependência do Brasil, em seu passado colonial, do planejamento da metrópole, somada ao tipo específico de ocupação territorial que aqui vivenciamos e que estava reconhecidamente presa a um projeto de extração contínua das riquezas, poderiam ser argumentos básicos para o entendimento de nossa visão de desenvolvimento. Comparando nossas tensões econômicas duradouramente agrárias e a adesão muito posterior do país ao quadro de modernização no sentido europeu do termo, fica evidente a juventude dos projetos de desenvolvimento nos termos também europeu-ocidentais.

Com a vinda da família real portuguesa, os esforços nesse caminho de racionalização institucional foram redirecionados, por exemplo, através da participação nos mercados internacionais e da redefinição do papel do Estado. Ainda assim, como é possível imaginar se afastarmos o romantismo anacrônico, a noção de desenvolvimento 
enquanto alteração da qualidade de vida social estava muito distante da premissa das elites gestoras portuguesas.

Mais tarde, quando a segunda metade do século XIX confirma o eco de nossa independência política, sob o governo de D. Pedro II inicia-se uma série de intervenções modernizadoras, como a instauração de linhas telegráficas, a criação da primeira linha férrea e reformas educacionais de modelo francês. Essa marca de imitação indica os primeiros passos efetivos de inscrição no projeto moderno e, ainda que parte da agenda das elites do Império, implica na reformulação do sentido da entidade estatal.

Ao longo dos fins do século XIX, já dada a República, e dos anos 1910 e 1920, a mudança seguirá para a formação de uma cultura da burocracia, de uma ampliação dos projetos de urbanização e catalogação das transformações de infraestrutura. A história cruzará os anos seguintes na formação de um corpo racional efetivo no governo Vargas. 240 Levará, dessa forma, mais de um século, desde a consolidação da independência, e sob o movimento do desenvolvimentismo industrializante de Juscelino Kubitschek (JK), para que o Brasil, já convertido em um Estado de aspirações racional-burocráticas desde os anos 1940, atinja a agilidade de crescimento exigida dentro do jogo produtivo do capitalismo internacional do pós-guerra.

Temos, no país, dois grandes períodos em que essa premissa desenvolvimentista ganha significados e contornos mais claros, para além da meta de reestruturação nacional. Primeiro, os anos 1970 virão repensar o projeto e a ideia de desenvolvimento nos termos regionais, alocando as preocupações administrativas e toda a imaginação pública no exercício de transpor as diferenças das regiões brasileiras em direção a uma organização econômica coordenada que levasse em conta os desafios pontuais de cada cenário. Em seguida, nos anos 1980 (com o agravamento das limitações dos projetos anteriores), a compreensão de que o desenvolvimento 
merecia dimensão e redesenho local veio como síntese tanto de questionamentos de planejamento e execução como de uma pulverização política que ganharia terreno nas dinâmicas de municipalização dos recursos e atribuições do Estado na microesfera das cidades (LIMA, 2011).

Essa rápida síntese de períodos e rupturas é apenas uma ilustração simplificada dos caminhos complexos pelos quais o Estado como máquina de composição das definições com capacidade para tal - ganhou formas. As referências ao modelo brasileiro de desenvolvimento prestam-se exatamente à teia mencionada: teoria e política articularam diálogos de variada proximidade e abrangência, construindo um campo poroso no entendimento dos projetos. Respeitando nossa viagem cronológica inicial, vamos ao segundo governo Vargas: sua leitura estruturada de Estado burocrático é a porta inicial das conjecturas renovadas da racionalização necessária às promessas e realizações do moderno. É no fim dos anos 1940 e começo dos anos 1950 que o projeto de articulação da máquina já encontra autonomia razoável diante do patriarcado artesanal das lideranças políticas tradicionais. A partir desse momento, estão fincadas as bases para as transformações promovidas - e idealizadas no plano de um projeto ressignificado - por JK. Definir (o Brasil, seus problemas, suas soluções) passa a representar papel estatal porque imediatizava o valor do Estado como lócus das resoluções.

Décadas depois, após um duplo período intercalado de planificação militar e inventivas neoliberais ${ }^{2}$, o desenvolvimento volta à baila sob o discurso da inclusão e do pacto nacional. A mudança geral dos discursos de gestão do Estado no período da gestão de Luiz Inácio Lula da Silva pode ser enquadrada dentro de quatro aspectos fundamentais: 1)

\footnotetext{
2 Tanto o período do Regime Militar quanto o da Redemocratização representam, naturalmente, lugares de fala importantes, mas não nos deteremos aqui neles para que o destaque seja dado a uma recuperação das falas públicas sobre desenvolvimento como pacto social - que segundo esta tese vincula Juscelino Kubitschek e Lula.
} 
a instauração inicial de uma "ética" administrativa - que sofrerá duros abalos nos anos de mandato; 2) a definição da relatividade sociocultural como marca exemplificada no slogan "Brasil, um país de todos"; 3) o combate imagético da desigualdade extrema e da miséria como bandeiras de ação; e 4) a defesa constantemente comparada da criação de infraestruturas negligenciadas ou desmontadas nas gestões anteriores (apontada "como fórmula política" do Partido da Social Democracia Brasileira - PSDB). Para os fins desta tese, o terceiro e quarto pontos são centrais, porque inspiram curiosidade sobre a oferta do imaginário contemporâneo.

A crítica à privatização é o primeiro princípio deste aspecto. Ela retrata a base conjuntural das falas do Partido dos Trabalhadores (PT) sobre o tratamento da máquina pública. Não é, como facilmente se pensa, uma referência direta ao modelo de desenvolvimento em si, mas constitui, certamente, um dos invólucros de uma contraproposta. Em março de 2010, Lula retoma a recorrente crítica:

Tentaram privatizar o Banco do Brasil. Tentaram até mudar o nome da Petrobras e quebraram o seu monopólio. Ferrovias não foram nem privatizadas, foram dadas a determinados grupos empresariais que fizeram os investimentos necessários. ${ }^{3}$

Longe de pautar-se como "novidade", a crítica à privatização estava presente já nos anos 1990, como parte da pauta do PT como oposição. Ela registrava uma das características ideológicas de um partido que nasce alimentado por oposições ao neoliberalismo que emergia na América Latina há mais tempo. Ao mesmo tempo, tal crítica será parteira de

\footnotetext{
3 Disponível em: <http://politica.estadao.com.br/noticias/geral,lula-ataca-privatizacoes-do-governo-fhc,522333>. Acesso em: 20 jun. 2017.
} 
uma defesa de ampliação de investimentos públicos na organização tanto de uma infraestrutura que permitisse o crescimento de um mercado interno quanto uma que ampliasse o que se convencionou chamar de "qualidade de vida" da maior parte possível da população. Este apontamento é importante na medida em que descreve a complexa separação aparente entre os discursos dos grupos que governaram o Brasil entre 1994 e 2010. Analisando o plano geral de ambas as "eras administrativas", é possível duvidar de uma separação tão simples, sendo mais plausível a observação que os discursos de oposição eram produzidos dentro das lacunas deixadas pela situação. Fica patente que nenhuma das forças em disputa (o PSDB e o PT, ambos com alianças em constante negociação) se definia pelo rompimento com uma política econômica industrial e ligada ao capital financeiro, separando-se nos anos 1990, quando muito, dentro de temas como papel e formato do Estado e estrutura geral das prioridades políticas em termos de público-alvo. Ainda assim, é na produção desse campo discursivo que percebemos a emergência de falas que, colocadas em prática ou não, pautavam-se em uma reordenação imaginária do Estado enquanto personagem político. Uma reordenação, como sugiro antes, baseada na oposição e reescritura dos vazios narrativos do grupo no poder.

A partir de 2003, o cenário nacional contempla um novo modelo de apresentação da máquina pública e um conjunto de "slogans" que a reconstroem aos olhos dos observadores. Essa "nova" máquina tomará de empréstimo a antiga discussão sobre desenvolvimento industrial-nacional como transformação da sociedade - especialmente forte no Brasil entre os anos 1930 e final dos 1950 -, incutindo em seu significado atual a premissa de que a União - e, mais especificamente, o Executivo - tem decisivo lugar na solução das desigualdades e carências da realidade brasileira. Essa concepção de um Estado planejador e gerador de demandas produtivas 
por intermédio de antecipações infraestruturais se fazia presente na Era Vargas, na concepção de intelectuais como Roberto Campos (FERREIRA, 2005) e no pensamento isebiano de Hélio Jaguaribe, ainda nos primórdios do Governo JK. É, aliás, à imagem desse governo e seu presidente que o PT e seus aliados buscaram, ao longo dos anos, vincular a imagem do presidente Lula: "Devemos seguir o exemplo de Juscelino Kubitschek, que soube transformar seus sonhos em conquistas e benefícios para o Brasil". ${ }^{4}$ Tal comparação, usada em diversas outras ocasiões, passa a fazer parte de um subtipo discursivo recorrente nos dois lados do espectro político, reiterando a impressão de que a memória pública do desenvolvimento e de seus personagens estava em uso. Mais tarde, é o candidato à presidência José Serra (PSDB) que evocará Juscelino para criticar o então presidente no pleito de 2010: "nunca vi o Juscelino numa campanha atacando pessoalmente adversários. Esse era um exemplo de 244 conduta boa de um presidente da República”. ${ }^{5}$

Somadas às disputas eleitorais, que funcionam como contexto imaginativo dos últimos anos de mandato de Lula e dos primeiros da então nova presidente Dilma Rousseff, está o grande debate acerca dos vácuos estruturais que, alegava a anterior oposição petista, assolavam a gestão de Fernando Henrique Cardoso - entre os quais aqueles ligados aos problemas de fornecimentos elétricos de 2001 e 2002, chamados à época de "apagão”, bem como os problemas enfrentados pela administração petista no âmbito dos transportes aéreos, quatro anos mais tarde. O segundo, também apontado como de responsabilidade dos governos

\footnotetext{
4 Declaração proferida por Lula em 3 de março de 2006, durante almoço oferecido ao primeiro-ministro da República Tcheca. Disponível em: <http://www1. folha.uol.com.br/folha/brasil/ult96u76207.shtml>. Acesso em: 20 jun. 2017.

5 Declaração proferida em 24 de setembro de 2010 em carreata pelo interior de Minas Gerais. Disponível em: <http://oglobo.globo.com/pais/eleicoes2010/ mat/2010/09/24/serra-evoca-juscelino-kubitschek-para-criticar-lula-921153226. asp >. Acesso em: 20 jun. 2017.
} 
anteriores, retorna como debate acerca das condições estruturais do país tendo em vista proximidade de dois eventos internacionais de vulto que aqui foram sediados: a Copa do Mundo de Futebol, em 2014, e as Olimpíadas do Rio de Janeiro, em 2016.

A resposta administrativa e política a tal vazio estrutural veio na forma das duas etapas do alardeado Programa de Aceleração do Crescimento (PAC), apresentado em 2007 e cuja segunda encarnação surge em 2010. O PAC e o PAC 2 foram exercícios de investimento em larga escala, voltados, sobretudo, para as áreas de infraestrutura, buscando elaborar uma resposta tanto prática quanto simbólica ao período administrativo anterior. Mas nos interessa aqui entender, sobretudo, seu primeiro sentido. Ainda em 2010, Lula afirmava:

O que nós estamos querendo é dar fôlego para que este país possa pensar o futuro, em que um presidente da República venha a fazer um discurso e ele não tenha que ficar falando mal de quem saiu, e que ele tenha que apresentar propostas à frente, propostas para os nossos netos, para os nossos filhos.

E é isso que eu acho que nós fizemos, com todas as mudanças. Vocês estão lembrados que em 2007 eu disse, no começo do segundo mandato: é preciso destravar este país. (DISCURSO..., 2010a, p. 7)

Ainda no mesmo discurso:

Na medida em que o Brasil aprendeu a se planejar, na medida em que nós estamos construindo... eu considero isso, Dilma, uma carteira, uma carteira de obras. [...] Então, o que nós estamos construindo no Brasil é uma prateleira de projetos nas prefeituras, nos estados e no governo federal para que quem vier a governar este país, em 
qualquer momento, não pegue o país como vocês pegaram as prefeituras, como vocês pegaram os governos dos estados e como nós pegamos aqui, em que você não tinha projeto. Tudo, você tinha que começar praticamente do zero. (DISCURSO..., 2010a, p. 6)

Sobre a relação dos investimentos com determinados espaços regionais outro discurso convoca ideias:

Nós estamos fazendo... Eu... Se o Celso Furtado fosse vivo, ele seria convidado a ir fazer uma visita ao Canal do São Francisco. Ele iria ver o que pode significar para o Nordeste um sonho acalentado desde 1847, por Dom Pedro e que nós só conseguimos fazer em 2005, depois de muita briga, depois de muito debate, depois de muita ação judicial, depois de muita luta, nós agora, finalmente, estamos com mais ou menos $50 \%$ em um eixo e $70 \%$ em outro eixo. Eu penso que a companheira Dilma Rousseff vai poder inaugurar uma coisa que significará quase um milagre para o estado do Rio Grande do Norte, para uma parte da Paraíba, de Pernambuco e do Ceará. Ou seja, são praticamente 12 milhões de brasileiros e brasileiras que vão, pela primeira vez, estar mais próximos da água, e eu espero que a gente consiga fazer bom uso dessa água, para justificar todo o investimento que nós fazemos. (DISCURSO..., 2010b, p. 2)

O que essas declarações implicam, além da prática de disputa em um campo permeado por agendas e armas discursivas? Em que ponto o desenvolvimento reapareceu como foco do debate e como incontáveis símbolos históricos passaram a ser usados dentro da atual encarnação do jogo de definições?

Ao estabelecer instrumentos de observação e reação diante de desafios naturais ou sociais, o Estado é pensado 
aqui como enunciador, definidor do que transforma, meio de produção simbólica. A noção de região, como parte de um conjunto político-material do fazer social e público, pode abrir caminhos para a reflexão. A ocupação física e imaginária de territórios humanos tem sido debatida nas ciências sociais com base em dois eixos clássicos: por uma antropologia das resistências, orientada por uma forte curiosidade acerca da formação e manutenção de processos identitários; e por um exame multifacetado da dinâmica das cidades, caracterizado, especialmente, por antropologias e sociologias urbanas. Em meio a isso, a ciência política continua organizando esforços transversais, em ambos os campos, na compreensão de rupturas e encadeamentos nas ideias de cidadania e no exame intermitente de políticas públicas com impacto regional, como forma de compreender aspectos do mesmo problema: como grupos e poderes sociais se relacionam na definição do espaço público-regional?

Esse resumo é menos que uma síntese simplista e parcial das questões que articulam espaço e sua construção social. A intenção geral aqui é, tão somente, ilustrar de forma inicial um conjunto de perguntas e problemas a qual a presente discussão se filia. Organizada dentro de um arcabouço de literatura especializada o debate que aqui integramos é fruto de intensos "recortes" que, esperamos, não deixem de lado a teia intricada de inquietações que o inspiraram. Há, obviamente, uma história de mudanças e configurações subjacentes a tudo isto. De modo que as contextualizações trabalhadas são necessárias a fim de que se entenda o lugar e o peso da região, e do estado, como partes de um corpus discursivo mais jovem - mas nem por isso recente - encarnado na noção de desenvolvimento.

No Brasil, da década de 1960 até o começo dos anos 2000, a noção de "desenvolvimento" sai da esfera abstrata das aspirações ideológico-discursivas para o ambiente, também conflituoso, das ações públicas. Sem querer afirmar 
que este desenvolvimento, como interesse do Estado, seja exclusivo deste período é importante frisar o corte que essa ideia vivencia com o processo de industrialização brasileira e como, com o tempo, ela se tornará base dos discursos políticos, criando um imaginário de noções técnicas e de promessas transformadoras sem o qual a linguagem do poder atual seria muito diferente.

O Nordeste do Brasil, por exemplo, aparece como território demarcado por forças político-administrativas tradicionais vinculadas à posse do gado e da terra e, depois, a empreendimentos de indústria. Ele experimentou um redimensionamento de sua definição na emergência de uma modernização do atraso (NOBRE, 2009), projeto estruturado pela elite surgida na educação racionalizada e empresarial do eixo sul-sudeste no Brasil.

Quando pensamos o desenvolvimento como uma questão de gestão de recursos, o pensamos também como poten248 cialidades de um Estado executor. A história do desenvolvimento do Nordeste é uma história de criação de instituições e projetos nacionais - ou apenas como parte de promessas dos agentes de governo ou como ações diversas nesse sentido. É a história de um sistema de financiamentos e gerenciamentos dos problemas e de seus gargalos, que tomará forma na criação do Banco Nacional do Desenvolvimento Econômico (BNDES), no Banco do Nordeste do Brasil (BNB), na reestruturação de aparelhos públicos como o Departamento Nacional de Obras Contra as Secas (DNOCS) e a Superintendência de Desenvolvimento do Nordeste (SUDENE) e em instâncias mais jovens, partícipes do quadro de intenções de pesquisa acerca da "questão nordeste" como o Instituto Nacional do Semiárido (INSA). Este leque de sujeitos e funcionalidades não poderia ser analisado em sua totalidade sistêmica por um trabalho menor que uma investigação de décadas. Dessa forma, eles surgem, aqui, como personagens a se conhecer e como relações a se 
compreender no contexto já delineado do estudo proposto: partes de um histórico de publicidades estatais.

Na realidade do estado do Ceará (para tomar um exemplo mais específico), o desenvolvimento ganhará sentido discursivo tanto no plano da mudança econômica como no da mudança burocrática: a modernização do Estado estava em pauta nos anos 1980, com a ascensão do grupo de Tasso Jereissati. A história da modernidade e da modernização no estado está cruzada com projetos políticos de inserção, de transfiguração da realidade econômica e de apropriação do agrário como primeiro mundo a converter. É nesse sentido que expressões como sertão, semiárido, campo e interior ganham importantes significados. Elas estavam presentes quando da inauguração do debate sobre mudança para o Nordeste e foram operadas, ao longo das décadas do século $\mathrm{XX}$, como centros conceituais da ideia de desenvolvimento regional. $\mathrm{O}$ caso cearense se enquadra, assim, como uma das múltiplas realidades em que o desenvolvimento dependia da capacidade inicial de modificar aquelas realidades em ruralidade, alterando o panorama de sua economia e, consequentemente, de suas arestas políticas e econômicas (MARTINS, 2008).

A modernização emerge como projeto federal, entre 1950 e 1970 e elabora um todo de proposições regionais nos quais o Ceará será inserido. O Grupo de Trabalho para o Desenvolvimento do Nordeste (GTDN), criado em 1959, ilustra a vontade política de alocar o território nordestino no capitalismo racionalista que a industrialização do Sudeste liderava. Ou a ruralidade nordestina era convertida em uma produtividade agrária de tipo empresarial ou o projeto nacional de industrialização sofreria penalidades e atrasos. Esse espírito de comodificação do trabalho e da produção engendrou um tratamento público à região que atravessará os governos militares e desembocará em uma cultura política de intervenção pautada no investimento e na disputa 
entre planos da União e interesses de elites tradicionais locais. Sob inúmeros aspectos, o desenvolvimento encarava um desafio: a vitória necessária sobre antigos modelos de política; entraves aos intentos do mercado em expansão e da conversão capitalista brasileira.

A mesma história recente também registra, contudo, que essa dinâmica de disputa encontrou formatos diferentes nos estados, assumindo ora um caráter de embate direto entre o local e o federal (como no caso da Paraíba, com forças locais em oposição), ora encaixes e reencaixes de interesses de ambas as partes, em uma espécie de adaptação das forças locais ao novo jogo nacional (como no caso cearense) (ISMAEL, 2005). Essa relação diferente entre poderes e forças, alterou também o modo pelo qual o desenvolvimento virá a se popularizar com discurso. No meio de ambos, a ideia de validação das ações federais e o uso político das obras e mudanças se tornará parte da cul250 tura e da imaginação política - que articulava, em especial após o regime militar, a mudança econômica com a garantia de permanência das elites na aceitação popular. Com o fim definitivo do regime militar e a ascensão de outras elites, os contatos entre Estado, mudança econômica e legitimação colocará todo o conteúdo da modernidade em um novo prisma - pontuado, por sua vez, em um ciclo de valorização que vai do Estado interventor a capacidade de gerar desenvolvimento e do desenvolvimento a existência de condições racionais próprias de um Estado modernizado.

A ideia de desenvolvimento convoca, assim, a noção de Estado como instrumento de sua existência e execução. Desbravar algumas das características da segunda, como fizemos aqui, é redesenhar os caminhos de formação da primeira. Em outras palavras e desafiando a compreensão por meio de uma simplificação: entender o que o Estado faz é entender o que ele é. A ideia de que o Estado é causador e planejador do desenvolvimento não é nova, como, discutido. 
Ainda assim, entender parte desses elos ainda se faz necessário, como instrumento de nova síntese: as das relações conceituais entre mudança social e estratégias de validação do poder.

Não é novidade, no conjunto de debates da Teoria Social, que o Estado se converte como uma máquina pautada pela legitimidade. As produções clássicas da filosofia e sociologia sugeriam ou afirmavam diretamente este signo. A ciência política, herdeira das concepções de ambas, discute os desdobramentos e mesmo a veracidade completa desta afirmação (GUNTHER; MONTEIRO, 2003), mas não a ignora. Talvez porque a discussão sobre legitimidade incorpore uma conturbada disputa do castelo teórico da própria concepção de política e de democracia. A ideia de que o poder é exercido não pela simples aplicação da força - ao contrário, a violência é símbolo de seu desaparecimento (ARENDT, 2004) - mas por um conjunto de aceitações e atribuições da sociedade para com um ou mais líderes considerados dignos, capazes ou, de uma maneira ainda mais ampla, autênticos, permite e leva aos diversos estudos de formação da esfera do Estado moderno e de sua consolidação. Ainda nos clássicos gregos, o ideal platônico-socrático de uma República perfeita era fundado em uma metáfora de estirpes de metal sabidamente falsa ${ }^{6} \mathrm{O}$ mito fundador da desigualdade nada mais era do que a fabricação do aceitável, da lógica que permitiria explicar as desigualdades indômitas que atravessavam o mundo antigo e que também atravessariam a feição de uma cidade ordenada.

\section{Considerações finais}

Buscamos observar e estabelecer uma rota interpretativa acerca do Estado como agente que enuncia e do desenvolvimento como linguagem. Ao pensarmos um e outro, seja no

${ }^{6}$ Vide A república de Platão e o diálogo entre Sócrates e Glauco. 
traço da história de suas produções no imaginário, na ação estrutural ou na esfera conceitual das ciências do homem, interagimos com a exteriorização dessas ideias no discurso sobre o contemporâneo. No Ocidente da acumulação primitiva e no Brasil das falas sobre a superação do agrário, o Estado-que-age converte-se em necessidade na ótica política e em suas exposições. Por fim, ao adentrarmos no Nordeste como encarnação de região definida ou de região a definir, testemunhamos essa ação concreta que une Estado e desenvolvimento em um ato. Ambos, configurados pelas expectativas de ordem, melhoria ou negação do atraso, incidem sobre o território para revelar esse poder conquistado - que não é nem absoluto, nem nominal - de definir lugares e cenários.

É justo fecharmos, para os fins deste texto, nossa viagem conceitual. Na era moderna, após tantas reflexões contratualistas e uma longa herança que misturará liberalismo e iluminismo, a legitimidade ressurgirá como uma ontologia 252 racionalizante e teológica: como Espírito Absoluto em Hegel. O historicismo da "teodiceia" hegeliana propõe compreender o passado e o processo de formação como a caminhada do Divino, levando a composição de uma ideia de Estado e do poder legitimada não apenas pelo senso do religioso e pelo arrebatamento para com a sua verdade, mas através da validação do vivido - cujo sujeito, neste caso, é a própria Humanidade. O holismo e a grandiosidade da proposta de Hegel transforma o poder legítimo em uma reverência necessária para com o conjunto gigantesco de fatos acumulados, de experiências transpostas pela História. A legitimidade do poder seria uma legitimidade transcendente rumo ao não humano e rumo ao passado.

A tradição alemã seguinte colocará as inversões conhecidas ao modelo hegeliano, mas ele não será esquecido. Mesmo quando Marx destrói as inerências da legitimidade ao apontar a carga ideológica na qual ela tem se sustentado, ainda que ele registre a longa batalha que se trava fora dessa 
ontologia (batalha que na verdade a sustenta) e coloque o material como base da discussão sobre poder e controle, é com o socialismo científico surgido de sua obra que a legitimidade voltará à baila como produto da História. A ideia de uma "classe revolucionária" estimulou, durante décadas, o pensamento da legitimidade datada da burguesia (se observarmos, por exemplo, os longos debates sobre a necessidade da consolidação do capitalismo para a futura tomada de poder parte das classes trabalhadoras). Do mesmo modo, criou a ideia de uma classe legitimamente capaz de reverter a própria existência da luta e dos sistemas de opressão: em Marx, o proletariado é dotado de uma autenticidade e de uma perspectiva histórica que lhe dá todos os direitos futuros sobre a mudança social. E ainda que esta compreensão dos movimentos políticos seja fruto mais de uma interpretação do passado do que uma "profecia”, ela organizou o pensamento social da esquerda no mundo, criando uma leitura de legitimidade paralela e oposta a definição hoje hegemônica do conceito - que deve seu formato à contribuição de Max Weber.

A noção de múltiplos nexos causais para o surgimento e consolidação da legitimidade tem nos trabalhos de Weber uma descrição sintética: fruto do carisma, da tradição e de versões racionais da prática do poder, a dominação não existe sem a legitimidade. É com base nisso, mas como já dissemos, sem abandonar o largo debate que o marxismo incorporou, que o debate sobre as dimensões do legítimo chegarão à sociologia política, a ciência política e aos estudos diversos da cultura do político. O reconhecimento de uma legitimidade pautada sobre diversas bases traz para a Teoria Social um novo conjunto de questões. Que agentes a disputam? Como é seu processo de formação dentro de uma sociedade? Quais as mudanças pelas quais passa, no contexto das alterações do cenário cultural e econômico dos grandes Estados e das formas de poder neles? 
No fim dos anos 1990, o trabalho do sociólogo espanhol Manuel Castells (1999) se juntará a elipse de discussões sobre o Estado moderno e a chamada "Era da informação". Evitando o debate cultural sobre "modernidade" e "pós-modernidade", este autor conjura outro conjunto de problemática para a compreensão das crises e desenvolvimentos sociais do Ocidente desde os anos 1970. Como vimos antes, neste mesmo trabalho, as temáticas discutidas por este autor incluem o Estado e as diversas premissas sobre seu destino e seu papel recente na conjuntura cultural e tecnológica de um tempo de múltiplas redes virtuais e comunicativas. Uma das respostas que Castells organiza diz respeito ao lugar instável do poder estatal no cenário das megacorporações transnacionais e no palco de uma imprensa rica na noticiabilidade do escândalo político. Seja no primeiro caso, em que está em questão o monopólio e a centralidade da máquina pública, seja no segundo, em 254 que as formas de acessá-la e geri-la, bem como os agentes envolvidos no processo, sofrem choques interno e externos constantemente, temos uma semiconclusão polêmica: o Estado perde território e se desarticula frente a uma crise de legitimidade.

A legitimidade do Estado-nação como agente gestor de uma sociedade está mesmo em xeque? Quando medimos sua (in) eficiência em se opor a outras forças sociais (CASTELLS, 1999; BAUMAN, 2011), quando examinamos a dependência de sua operacionalização mediante um largo apoio externo (GIDDENS, 1990), a resposta tende a ser sim. Não obstante, a afirmação cria mais dúvidas sobre o papel e o funcionamento de suas instituições formadoras, fazendo com que, ou por meio de um exame de suas competências ou mediante uma análise de suas reações diante da sociedade, voltemos à ideia de legitimidade como local privilegiado para o entendimento do contexto em debate. Quais os caminhos e sujeitos ligados à formação da legitimidade? 
No caso do Estado brasileiro e de sua formação, pautada nos embates ideológicos - primeiro da Independência, depois da República - e em seguida nas diversas reestruturações vividas no século XX - que têm em comum o histórico de clientelismos fortíssimos e de um patrimonialismo ainda latente - lidamos com uma máquina que apenas recentemente encontrou um caminho de racionalização burocrática na democracia. Para os clássicos da questão, essa juventude democrática está cercada, sem dúvida, pela marca da ratio incompleta, constantemente assombrada pela cultura de um "capitalismo dependente". Nesse contexto, instituições capazes de vencer a incerteza presente na estrutura moderna da política, criando parâmetros de confiança e autenticidade em um torneio simbólico de aparições públicas, se fazem cada vez mais necessárias. Mas quais os dispositivos políticos deste processo de conquista de uma legitimidade funcional? Quais os meandros de sua criação e desenvolvimento no campo do publicado? Como podemos entender sua dinâmica, seu movimento e seus propósitos mais específicos?

A ideia de meios de produção da definição busca recortar os modos de fala e exposição estatais, para lembrar às análises sociais que este é um momento de burocracias expostas e de documentações comunicativamente públicas. O conceito de era da informação e a premissa de que grandes mecanismos institucionais articulam o saber e o poder (FOUCAULT, 2004) são o epicentro desta concepção. Ao percebermos que o discurso público se torna arma de pressão entendemos que a internet, por exemplo, em suas várias encarnações, anima a capacidade de legitimar por intermédio do informe. $\mathrm{O}$ dito estatal, nesse meio, é uma voz difusa. Captá-la e compreender os sistemas que dão vida a ela não seriam um modo articulado de atualizar a interpretação sociológica? 


\section{Mário Henrique Castro Benevides}

é professor adjunto do Instituto de Humanidades e Letras da Universidade da Integração Internacional da Lusofonia Afro-Brasileira (UNILAB).

\section{Bibliografia}

ARENDT, H. 1994. Da Violência. Petrópolis: Vozes.

BAUDRILLARD, J. 2007. A sociedade de consumo. Lisboa: Edições 70.

BAUMAN, Z. 2011. 44 cartas do mundo líquido moderno. Rio de Janeiro: Zahar.

BOURDIEU, P. 1992. A economia das trocas simbólicas. São Paulo:

Perspectiva.

CASTELLS, M. 1999. A era da informação: economia, sociedade e cultura. São

Paulo: Paz e Terra.

DARNTON, R. 1990. O Beijo de Lamourette. São Paulo: Companhia das

Letras.

DISCURSO do Presidente da República, Luiz Inácio Lula da Silva,

durante cerimônia de lançamento do Programa de Aceleração do

Crescimento (PAC 2). 2010a. Brasília: Presidência da República.

Disponível em: <http://bit.ly/2sMJCZH>. Acesso em: 20 jun. 2017.

256 DISCURSO do Presidente da República, Luiz Inácio Lula da

Silva, durante cerimônia de outorga do Prêmio Nacional de

Desenvolvimento Regional - Edição 2010: Homenagem a Celso

Furtado. 2010b. Brasília: Presidência da República. Disponível em:

<http:/ /bit.ly/2tJQRib>. Acesso em: 20 jun. 2017.

FAÉ, R. Os discursos sobre desenvolvimento como recursos politico-estratégicos:

o banco mundial como organização central no campo discursivo do

desenvolvimento. 2009. 263 p. Tese (Doutorado em Administração) -

Escola de Administração, Universidade Federal do Rio Grande do Sul,

Porto Alegre, 2009.

FAORO, R. 2008. Os donos do poder: formação do patronato político brasileiro.

São Paulo: Globo.

FOUCAULT, M. 1999. Arqueologia do saber. São Paulo: Vozes. . 2004. A ordem do discurso. São Paulo: Loyola.

GIDDENS, A. 1990. As consequências da modernidade. São Paulo: Unesp.

GUNTHER, R.; MONTEIRO, J. R. 2003. Legitimidade política em novas

democracias. Revista de Opinião Pública, v. 9, n. 1, pp. 1-43.

HEGEL, G. W. F. 1974. A fenomenologia do espírito; estética, a ideia e o ideal; estética, o belo artístico e o ideal: introdução a história da filosofia. São Paulo:

Abril Cultural. 
HOBSBAWM, E. J. 1986. História do Marxismo, VII: o Marxismo na época da terceira internacional: a URSS da construção do socialismo ao stalinismo. Rio de Janeiro: Paz e Terra.

. 1998. A era das revoluções: Europa 1789-1848. 11. ed. Rio de Janeiro: Paz e Terra.

HUNT, E. K.; SHERMAN, H. J. 2008. História do pensamento econômico. 24. ed. Petrópolis: Vozes.

ISMAEL, R. 2005. Nordeste: a força da diferença: os impasses e desafios na cooperação regional. Recife: Massangana.

LIMA, M. C. 2011. Região e desenvolvimento do capitalismo contemporâneo: uma interpretação crítica. São Paulo: Unesp.

MARTINS, M. D. 2008. Açúcar no Sertão: a ofensiva capitalista no Nordeste do Brasil. São Paulo: Annablume.

MELLO, F. P. 2009. A guerra total de Canudos. São Paulo: A Girafa.

SUNY, R. G. 2008. Ascensão e queda da União Soviética: o império de nações. Lua Nova, n. 75, pp. 77-98.

WEBER, M. 2004. Economia e sociedade. Brasília: Imprensa Oficial. 


\section{OS "MEIOS DE PRODUÇÃO DA DEFINIÇÃO":}

\section{DESENVOLVIMENTO, REGIONALIZAÇÃO E PODER NA AÇÃO DISCURSIVA DO ESTADO NO BRASIL}

MÁRIO HENRIQUE CASTRO BENEVIDES

Resumo: Este artigo expõe uma ferramenta conceitual que permite observar a ação histórica do Estado no Brasil, tomando principalmente sua capacidade de definir territórios e ações por meio de seu discurso institucional e legitimador. Demonstra-se, dessa maneira, que as ciências sociais precisam captar as injunções entre a narrativa pública e os "meios de produção da definição" produzidos no seio das afirmações estatais. Mediante síntese histórico-teórica dos governos Lula e seu aspecto desenvolvimentista, bem como do pensamento analítico sobre a modernidade, argumenta-se no texto que ideias como região e desenvolvimento são partes intercaladas para uma genealogia das formas de classificação que a máquina pública engendra. Pensar esses elementos é orientar ferramentas de análise em sociologia política.

Palavras-chave: Meios de Produção da Definição; Estado e Discurso; Economia das Trocas Simbólicas.

\section{“MEANS OF PRODUCTION IN DEFINITION": DEVELOPMENT, REGIONALIZATION, AND POWER OF STATE'S DISCOURSIVE ACTION IN BRAZIL}

Abstract: The article shows a conceptual tool for observing the State's historic action in Brazil. This concept is based on the analysis of the State's capacity to define territories and actions through its institutional discourse, which has a power of legitimation. In this way, the text demonstrates that the social sciences need to collect the injunctions between public narrative and the "means of production in definition" which are made in State's speech. The analytic 
thought of modernity is the theoretical basis of this study. By means of a historical and theoretical synthesis of Lula's government and its developmental discourse, the paper explains that ideas about region and development are parts of a genealogy of classification ways produced by the Public Machine. Thinking about these elements means to guide analysis tools in political sociology.

Keywords: Means of Production in Definition; Discourse and State; Economy of Symbolic Exchanges.

Recebido: 05/05/2015 Aprovado: 11/11/2016 